\title{
Mechanical Performance of Wood Under Artificial and Natural Weathering Treatments
}

\author{
Tiago H. Almeida, ${ }^{a}$ Diego H. Almeida, ${ }^{\mathrm{b}}$ Eduardo Chahud, ${ }^{\mathrm{c}}$ Luiz A. M. N. Branco, ${ }^{\mathrm{d}}$ \\ Roberto V. Pinheiro, ${ }^{\mathrm{e}}$ André L. Christoforo, ${ }^{\mathrm{f}, *}$ and Francisco A. R. Lahr ${ }^{\mathrm{g}}$
}

\begin{abstract}
Natural and artificial weathering treatments were studied to determine the change of wood properties as a function of exposure time. This paper aimed to provide general information about the mechanical performance of wood under natural and artificial weathering treatments and define a relationship between them. The eight strength classes of ABNT NBR 7190 (1997) were considered, in addition to a paired sampling approach. The modulus of elasticity and conventional strength value in static bending, strength in compression parallel to the grain, hardness perpendicular to the grain, and the elastic limit in the static bending test were investigated. Linear regression models for mechanical performances under artificial and natural aging treatments of the exposure time were made and tested using an analysis of variance. According to the results, 360 days of natural weathering provoked a change in mechanical performance of $15.72 \%$ that included a decrease in strength and modulus of elasticity and an increase in elastic limit. Twelve hours of the artificial weathering treatment provided the effect of 6.22 days of natural weathering exposure.
\end{abstract}

Keywords: Artificial weathering; Mechanical performance; Natural weathering; Timber structures; Wood

Contact information: a: Department of Science and Materials Engineering, Engineering School of São Carlos, University of São Paulo (EESC/USP), São Carlos, Brazil; b: Department of Civil Engineering, Federal University of Rondônia (UNIR), Porto Velho, Brazil; c: Department of Civil Engineering, Federal University of Minas Gerais (UFMG), Belo Horizonte, Brazil; d: Department of Civil Engineering, Municipal Foundation for Community Education, Belo Horizonte, Brazil; e: Department of Civil Engineering, Mato Grosso State University (UNEMAT), Sinop, Brazil; f: Department of Civil Engineering, Federal University of São Carlos (UFSCar), São Carlos, Brazil; g: Department of Structures Engineering, EESC/USP, São Carlos, Brazil; *Corresponding author: christoforoal@yahoo.com.br

\section{INTRODUCTION}

The civil construction industry is one of the most important sectors of wood utilization (Calil, Jr. et al. 2003; Almeida et al. 2017). Wood can be used as a structural material or as non-structural pieces (building elements such as doors, floors, etc.) in civil constructions (Almeida et al. 2017b). The Brazilian standard code ABNT NBR 7190 (1997) "Design of timber structures” provides procedures for the structural calculation for wood materials as well as physical-mechanical characterization.

According to this standard, there are three strength classes for softwoods (C20, C25, and C30) and five strength classes for hardwoods (D20, D30, D40, D50, and D60), totaling eight strength classes. The strength classes are determined by the characteristic value of the strength in compression parallel to the grain and are measured using defect-free specimens at a 12\% moisture content (Almeida and Dias 2016). According to Almeida et al. (2016), strength classes can be used for sampling in wood research and cover a range of wood densities. 
It is common to use wood for outdoor structures in above-ground environments (Viitanen et al. 2011; Mohebby and Saei 2015; Oberhofnerová et al. 2017). In this situation, wood materials are exposed to natural weathering, which pertains to rainfall incidence, dew, air humidity, and ultraviolet (UV) radiation (Rodríguez-Anda and FuentesTalavera 2003; Pandey 2005; Rosu et al. 2010). The UV light is divided into three wavelength intervals: UVA corresponds to radiations with wavelength values between 315 $\mathrm{nm}$ and $400 \mathrm{~nm}$, UVB corresponds to radiations with wavelength between $280 \mathrm{~nm}$ and 315 $\mathrm{nm}$, and UVC corresponds to radiations with wavelength between $100 \mathrm{~nm}$ and $280 \mathrm{~nm}$. A smaller radiation wavelength results in higher energy and penetration power of this radiation (George et al. 2005).

Weathering provokes wood degradation (Ganne-Chédeville et al. 2012; Cogulet et al. 2016), and accelerated artificial weathering treatments are used for simulating the natural aging process and to investigate its effects on properties of the wood (Fechine et al. 2006; Hansmann et al. 2006; Miklečić and Jirouł-Rajković 2011; Yildiz et al. 2011, 2013; Baysal 2012; Teodorescu et al. 2017). The artificial aging of nonmetallic materials was performed according to the standard ASTM G154 (2016).

For the design of timber structures it is important to understand the mechanical properties of the materials being used (Calil, Jr. et al. 2003; Almeida et al. 2016). The mechanical performance of wood under natural weathering treatments as well as mechanical performance changes under artificial weathering treatments must be investigated to understand the natural aging treatment and provide background for future research in this field.

This paper aims to investigate mechanical performance changes of wood under natural and artificial weathering treatments, covering all strength classes of the Brazilian standard code, to provide more general and useful information about the mechanical performance of aged wood. In addition, a relationship between the artificial and natural weathering treatments based on the mechanical properties of wood was determined.

\section{EXPERIMENTAL}

\section{Materials}

To perform this investigation, softwoods and hardwoods from the eight strength classes designated by the standard code ABNT NBR 7190 (1997) were considered. The softwoods chosen were Pinus sp. (divided into three strength classes - C20, C25, and C30). For hardwoods, five tropical Brazilian wood species were considered: Simarouba amara (D20), Anacardium giganteum (D30), Erisma uncinatum (D40), Bagassa guianensis (D50), and Peltogyne lecointei (D60). Each wood species representing a Brazilian standard code strength class came from certified forests in the northern region of Brazil.

All wood samples were at a $12 \%$ moisture content. For the aging procedures, these samples were made with dimensions of $20 \mathrm{~mm} \times 20 \mathrm{~mm} \times 320 \mathrm{~mm}$ (the largest dimension was in the grain direction) according to the standard code ABNT NBR 7190 (1997). There were three treatments completed: artificial weathering (artificially accelerated aging) was completed in three levels, natural weathering (natural aging) was completed in three levels, and the control was completed without any treatments. Six samples were tested for each wood species for each aging treatment in each level for a total of 288 samples. 


\section{Methods}

For better comparisons, each prepared aged sample had a control sample extracted from the same wood piece, which led to a paired sampling. The aged sample performance was compared to the control sample performance to minimize wood variability of the samples.

An artificial weathering chamber (Fig. 1a) was used to simulate the aging conditions for the material testing. The equipment (Artificial weathering chamber; Equilam, São Paulo, Brazil) reproduced UVA/UVB irradiation atmospheres with condensation/thermal shock, which simulated the effects of sunlight, rain, and dew exposure. The radiation sources were eight fluorescent lamps (40 W each) with wavelengths of $340 \mathrm{~nm}$ and $313 \mathrm{~nm}$ (UVA or UVB lamps, respectively), and an irradiation power of 0.47 to $1.60 \mathrm{~W} / \mathrm{m}^{2} / \mathrm{nm}$. Figure $1 \mathrm{~b}$ illustrates the sample arrangement for the natural aging treatment in an outdoor environment.

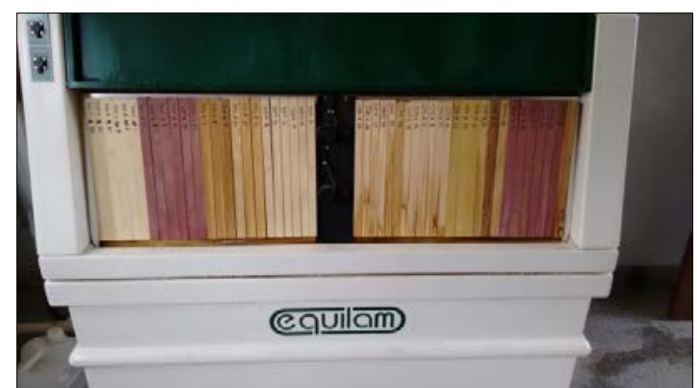

(a)

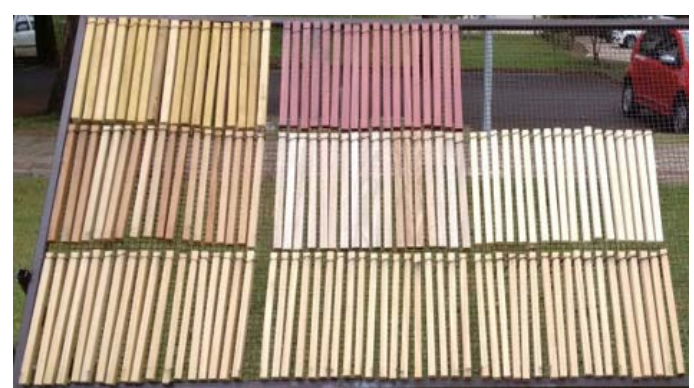

(b)

Fig. 1. Arrangement of samples for (a) artificial and (b) natural aging

Cycle 7 of the ASTM G154 (2016) was used with conditions of 8 h of UV irradiation at $60{ }^{\circ} \mathrm{C}, 15 \mathrm{~min}$ of water spray, and $3 \mathrm{~h}$ and $45 \mathrm{~min}$ at $50{ }^{\circ} \mathrm{C}$ of condensation, which totaled $12 \mathrm{~h} /$ cycle. The average irradiation was $1.55 \mathrm{~W} / \mathrm{m}^{2} / \mathrm{nm}$ using UVB lamps. There were 8, 16, and 32 cycles performed for the three levels of artificial weathering based on the observed visual effect of the aged samples (96, 192, and $384 \mathrm{~h}$, respectively, of artificial weathering exposure).

Weather conditions for the natural aging treatment were collected based on the data of Empresa Brasileira de Pesquisa Agropecuária- Embrapa [Brazilian Agricultural Research Corporation]. The Embrapa Station is located in São Carlos, São Paulo State, Brazil. The geographic coordinates of the weather station are $21^{\circ} 57^{\prime} 42^{\prime \prime}$ (S) latitude and $47^{\circ} 50^{\prime} 28^{\prime \prime}(\mathrm{W})$ longitude with an altitude of $860 \mathrm{~m}$. For artificial and natural aging, the wood samples did not receive any coating. To cover all four seasons of the year, 90, 180, and 360 days of natural weathering exposure were considered.

Mechanical tests were performed according to the annex B of the Brazilian standard code ABNT NBR 7190 (1997) that describes the procedures for physical-mechanical properties determination. The standard's items B.8, B.14, and B.15 are concerned with compression parallel to the grain, static bending, and hardness tests, respectively. The compression parallel to the grain tests were performed for strength in compression parallel to the grain $\left(f_{\mathrm{c} 0}\right)$ determinations. The static bending tests were performed for the longitudinal modulus of elasticity $(E)$, conventional strength value $\left(f_{\mathrm{m}}\right)$, and elastic limit $\left(L_{\mathrm{E}}\right)$ determinations. The hardness tests were performed in a perpendicular direction to the grain $\left(f_{\mathrm{h} 90}\right)$ for Janka hardness determination.

Figure 2 shows the universal testing machines that were used for mechanical 
characterization. Figure 2a presents the EMIC (EMIC, São Paulo, Brazil) with a $30 \mathrm{kN}$ capacity that was used for the static bending tests. Figure $2 b$ shows the AMSLER (Alfred J Amsler Company, Schaffhausen, Switzerland) with a 25-ton capacity that was used for the compression parallel to the grain and hardness tests.

Figure 3 illustrates the mechanical tests performed. Figure 3a represents the static bending test, Fig. 3b illustrates the compression parallel to the grain test, and Fig. 3c shows the hardness test performed.

The modulus of elasticity for the aged samples was determined in two directions: the most aged surface in tension $\left(E_{\mathrm{T}}\right)$ and the most aged surface compression $\left(E_{\mathrm{C}}\right)$.

As a means to minimize wood variability and make a more general approach (regardless of the wood species), the relative mechanical performance of the wood samples was considered (ratio between mechanical performance of aged and control samples), which made it possible to evaluate only the aging effects.

To investigate any of the mechanical performance changes with the exposure time to the aging treatments, linear regression models were performed using the ordinary least squares method and tested using an analysis of variance (ANOVA) at a 5\% significance level. The null hypothesis was the non-representativeness of the model ( $p$-value $>0.05$ ), and the otherwise, as an alternative hypothesis, the proven representativeness of the model (p-value < 0.05). For the statistical analysis the software $\mathrm{R}$ version 3.5.2 was used ( $\mathrm{R}$ Foundation for Statistical Computing, version 3.5.2, Vienna, Austria).

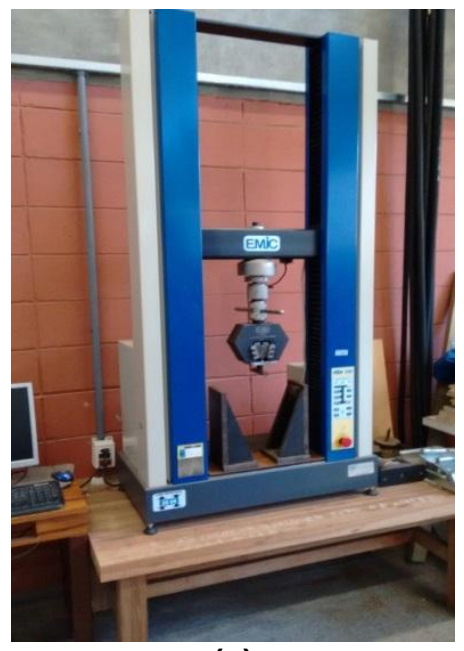

(a)

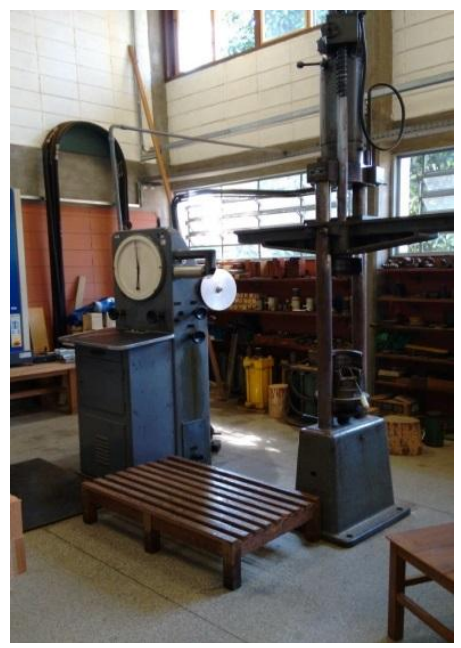

(b)

Fig. 2. Universal testing machines: (a) EMIC and (b) AMSLER

Linear regression models for the modulus of elasticities in static bending ( $E_{\mathrm{T}^{*}}$ and $\left.E_{\mathrm{C}}\right)$, conventional strength value in static bending $\left(f_{\mathrm{m}}\right)$, strength in compression parallel to the grain $\left(f_{\mathrm{c} 0}\right)^{\circ}$, hardness perpendicular to the grain $\left(f \mathrm{fh} 90^{\circ}\right)$, and the elastic limit in the static bending test $\left(L_{\mathrm{E}}\right)$ were performed for the natural and artificial aging treatments using relative values (ratio between control and aged sample performances - paired sampling).

For a better comparison of the natural and artificial weathering effects on the mechanical properties of the wood, boxplots of the relative values were made, as well as comparisons between the most aged relative mechanical performances (levels $3-384$ hours of artificial weathering and 360 days of natural weathering) with the unitary 
populational average. This average comparison was made with Wilcoxon's test at the same significance level, in which a p-value greater than $5 \%$ implied the average equivalence, and non-equivalence otherwise (p-value less than 5\%).

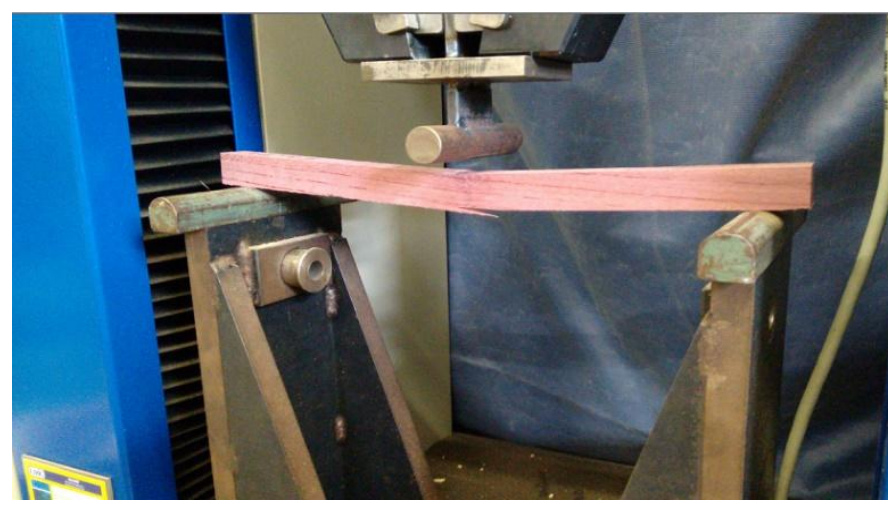

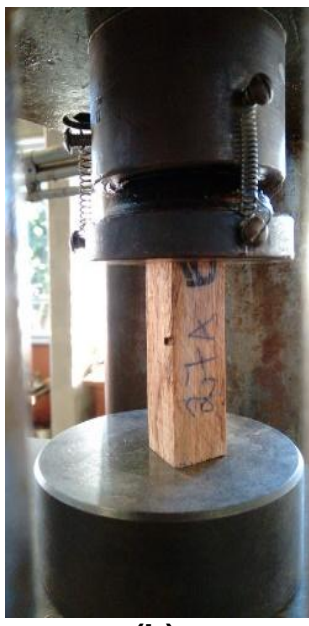

(b) (a)

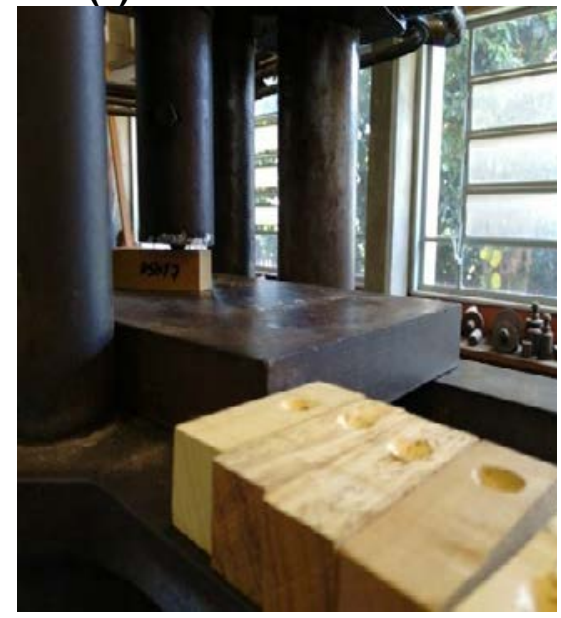

(c)

Fig. 3. Illustration of mechanical tests: (a) static bending, (b) compression parallel to the grain, and (c) hardness perpendicular to the grain

The decrease in relative mechanical performances as an effect of the aging treatments for the most aged wood samples (384 h of artificial aging and/or 360 days of natural aging) was determined using the confidence intervals of the adjusted linear models. Using these values helped to compare both weathering treatments based on the decrease in the mechanical performance that each treatment provided, and to calculate how many days of the natural aging treatment (at the same conditions) corresponded to one cycle of the artificial aging treatment $(12 \mathrm{~h})$.

\section{RESULTS AND DISCUSSION}

Meteorological data related to the temperature, relative air humidity, rainfall incidence, and solar irradiation at the natural weathering treatment location during 360 days of exposure were collected. Table 1 presents these results. 
Table 1. Summary of Meteorological Data

\begin{tabular}{|c|c|c|c|c|c|c|}
\hline Statistics & Average & CV (\%) & Min & Max & Sum & Count \\
\hline Temperature $\left({ }^{\circ} \mathrm{C}\right)$ & 18.26 & 14.89 & 11.20 & 23.70 & - & \multirow{4}{*}{$\begin{array}{c}90.00 \\
\text { (N1) }\end{array}$} \\
\hline Relative air humidity (\%) & 72.17 & 21.32 & 43.50 & 100.00 & - & \\
\hline Rainfall incidence (mm) & 2.87 & 258.58 & 0.00 & 34.30 & 258.40 & \\
\hline Solar irradiance $\left(\mathrm{MJ} / \mathrm{m}^{2}\right)$ & 14.26 & 31.67 & 2.97 & 19.75 & 1283.55 & \\
\hline Temperature $\left({ }^{\circ} \mathrm{C}\right)$ & 19.51 & 15.97 & 11.20 & 28.30 & - & \multirow{4}{*}{$\begin{array}{c}180.00 \\
(\mathrm{~N} 2)\end{array}$} \\
\hline Relative air humidity (\%) & 68.81 & 21.55 & 36.80 & 100.00 & - & \\
\hline Rainfall incidence (mm) & 2.25 & 277.82 & 0.00 & 34.30 & 405.60 & \\
\hline Solar irradiance $\left(\mathrm{MJ} / \mathrm{m}^{2}\right)$ & 16.76 & 33.15 & 2.97 & 27.60 & 3016.65 & \\
\hline Temperature $\left({ }^{\circ} \mathrm{C}\right)$ & 21.06 & 14.24 & 11.20 & 28.30 & - & \multirow{4}{*}{$\begin{array}{c}360.00 \\
(\mathrm{~N} 3)\end{array}$} \\
\hline Relative air humidity (\%) & 73.14 & 18.10 & 36.80 & 100.00 & - & \\
\hline Rainfall incidence (mm) & 4.03 & 221.28 & 0.00 & 48.80 & 1449.30 & \\
\hline Solar irradiance $\left(\mathrm{MJ} / \mathrm{m}^{2}\right)$ & 18.87 & 31.73 & 2.97 & 31.46 & 6792.39 & \\
\hline
\end{tabular}

In the southeast region of Brazil, there is high solar irradiation, high relative air humidity, and little variation in daily temperature. A total of $6792.39 \mathrm{MJ} / \mathrm{m}^{2}$ in solar irradiation (approximately $437 \mathrm{~J} / \mathrm{s} / \mathrm{m}^{2}$ for $12 \mathrm{~h}$ of radiation per day) covered the full range of wavelengths. For the artificial weathering treatment, the radiation used was concentrated only on UVB rays, which irradiated approximately $485 \mathrm{~J} / \mathrm{s} / \mathrm{m}^{2}$ with lamps of $313 \mathrm{~nm}$ wavelength.

The relative values of the mechanical properties were calculated after performing mechanical characterization that determined the modulus of elasticities ( $E_{\mathrm{T}}$ and $E_{\mathrm{C}}$ ), conventional strength value in static bending $\left(f_{\mathrm{m}}\right)$, strength in compression parallel to the grain $\left(f_{\mathrm{c} 0}\right)$, hardness perpendicular to the grain $\left(f_{\mathrm{h} 90}\right)$, and the elastic limit in the static bending test $\left(L_{\mathrm{E}}\right)$, for the aged and control samples.

These relative values $\left(E_{\mathrm{T}}, E_{\mathrm{C}^{\prime}}, f_{\mathrm{m}^{\prime}}, f_{\mathrm{c} 0}\right.$, $f_{\mathrm{h} 90}$, and $L_{\mathrm{E}}$ ) ) were used for linear regression model development of the mechanical performance of the wood by the exposure time to artificial or natural weathering treatments. Table 2 presents these linear regression models, where the "a”, "b”, $\mathrm{R}^{2}$, and P-value represent the intercept, slope coefficient, coefficient of determination, and P-value of the ANOVA tests, respectively. In Table 2, the significant models have underlined $\mathrm{P}$-values.

Table 2. Linear Regression Models Adjusted

\begin{tabular}{|c|c|c|c|c|c|}
\hline Property & Weathering & $\mathrm{a}$ & $\mathrm{b}$ & $\mathrm{R}^{2}$ & P-value \\
\hline$E_{\mathrm{T}^{\prime}}$ & Artificial & 0.9942 & -0.0002 & 0.0406 & $\underline{0.0003}$ \\
\hline$E_{\mathrm{C}^{\prime}}$ & Artificial & 0.9942 & -0.0002 & 0.0533 & $\underline{0.0000}$ \\
\hline$f_{\mathrm{m}^{\prime}}$ & Artificial & 0.9967 & -0.0002 & 0.0136 & $\underline{\underline{0.0269}}$ \\
\hline$f_{\mathrm{C}^{\prime}}$ & Artificial & 0.9994 & -0.0001 & 0.0040 & 0.1437 \\
\hline$f_{\mathrm{h} 90^{\prime}}$ & Artificial & 1.0060 & 0.0001 & 0.0020 & 0.4520 \\
\hline$L_{\mathrm{E}^{\prime}}$ & Artificial & 1.0247 & 0.0004 & $\underline{0.1083}$ & $\underline{0.0000}$ \\
\hline$E_{\mathrm{T}^{\prime}}$ & Natural & 0.9875 & -0.0003 & 0.0804 & $\underline{\underline{0.0000}}$ \\
\hline$E_{\mathrm{C}^{\prime}}$ & Natural & 0.9875 & -0.0003 & 0.0746 & $\underline{\underline{0.0000}}$ \\
\hline$f_{\mathrm{m}^{\prime}}$ & Natural & 0.9743 & -0.0004 & 0.0810 & $\underline{\underline{0.0000}}$ \\
\hline$f_{\mathrm{C}^{\prime}}$ & Natural & 0.9898 & -0.0003 & 0.0473 & $\underline{\underline{0.0001}}$ \\
\hline$f_{\mathrm{h} 90^{\prime}}$ & Natural & 1.0050 & -0.0001 & 0.0053 & $\underline{0.1126}$ \\
\hline$L_{\mathrm{E}^{\prime}}$ & Natural & 1.0310 & 0.0004 & $\underline{0.1448}$ & $\underline{\underline{0.0000}}$ \\
\hline
\end{tabular}


As shown in Table 2, only the $E_{\mathrm{T}}, E_{\mathrm{C}}, f_{\mathrm{m}}$, and $L_{\mathrm{E}}$, linear regression models were significant for the artificial weathering treatment (P-value $<0.05)$, which meant that the artificial aging influenced the mechanical properties of the wood. For natural weathering, the only model not influenced by the aging treatment was $f_{\mathrm{h} 90}$ ' (p-value $\left.>0.05\right)$, but it was significant for all other linear regression models.

Each adjusted linear regression model had 288 experimental data, among four exposure times (zero, level 1, level 2, and level 3) that negatively influenced the coefficient of determination due to the variability of mechanical performance changes with the aging treatments. The highest $\mathrm{R}^{2}$ value for the artificial aging linear regression models was $10.83 \%$, and the highest $\mathrm{R}^{2}$ value for the natural aging linear regression models was $14.48 \%$, which were both relative values from the elastic limit in the static bending tests.

\section{Artificial - Relative values}

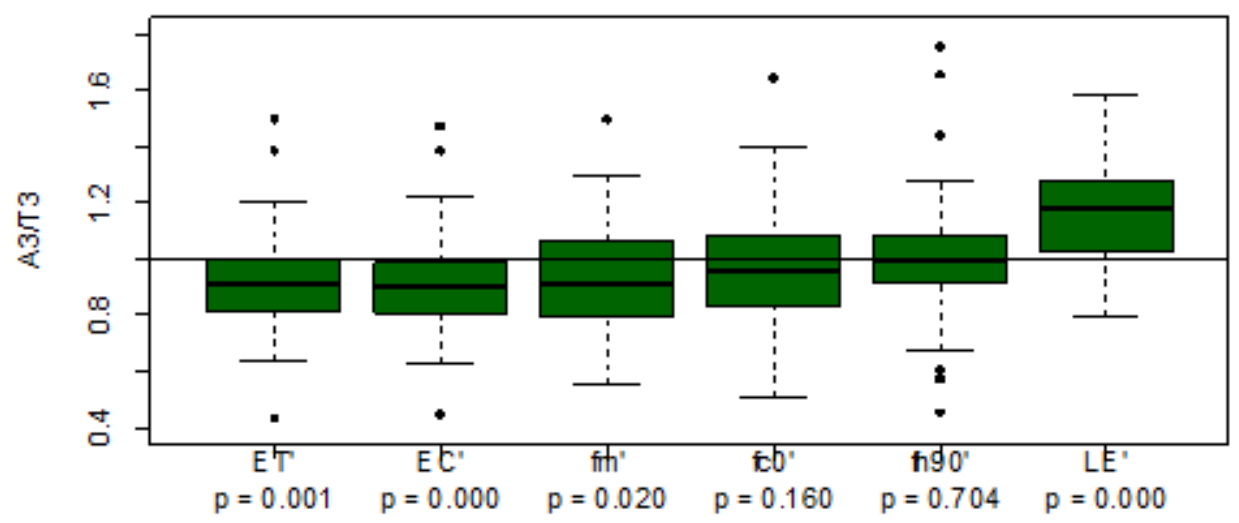

Fig. 4. Boxplots of relative values and Wilcoxon's tests for comparisons with the unitary populational average value for artificial aging

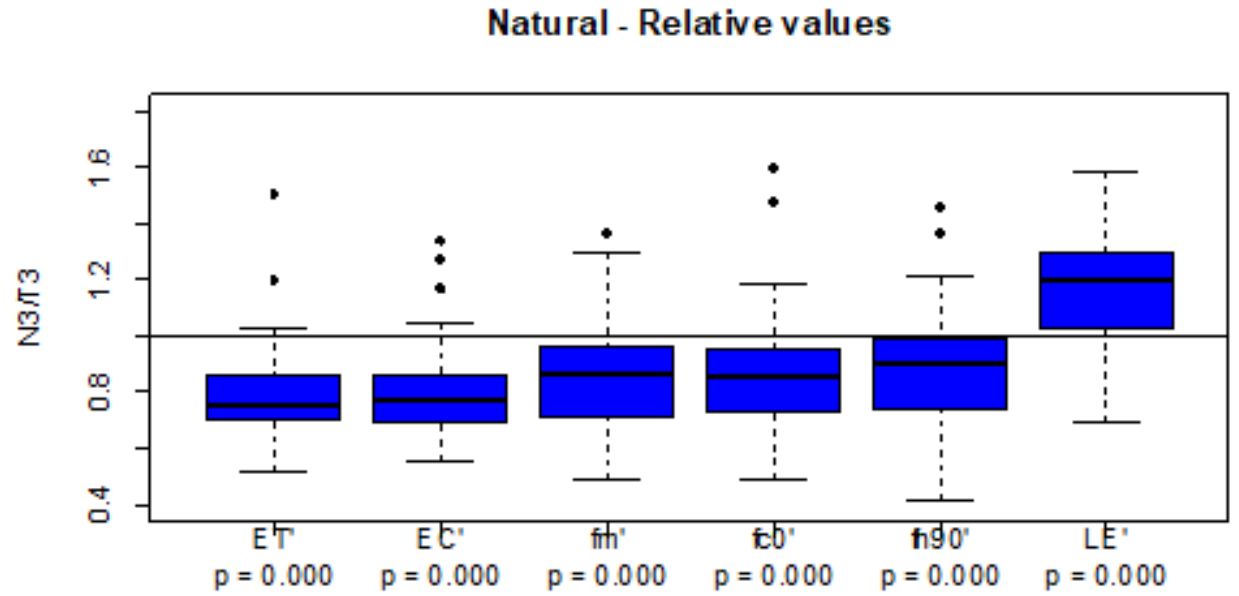

Fig. 5. Boxplots of relative values and Wilcoxon's tests for comparisons with the unitary populational average value for natural aging 
For better comparisons of the aging effects on the mechanical performances of the wood, boxplots of $E_{\mathrm{T}}, E_{\mathrm{C}}, f_{\mathrm{m}}, f_{\mathrm{c} 0}$, $f_{\mathrm{h} 90}$, and $L_{\mathrm{E}}$ were made. Figures 4 and 5 show these boxplots for the artificial and natural aging treatments (only for level 3 in relation to the controls), respectively. T3 Stands by the control samples performances. Wilcoxon's tests were performed for comparing the average relative values of the mechanical properties with the unitary populational average at a 5\% significance level. For Wilcoxon's tests, a pvalue greater than 0.05 was the equivalence between the average relative value and the unitary populational average, and the non-equivalence otherwise.

As shown in Fig. 4 for the artificial weathering treatment, only $E_{\mathrm{T}}, E_{\mathrm{C}}, f_{\mathrm{m}}$, and $L_{\mathrm{E}}$ ' presented non-equivalent average values compared to the unitary populational average value, which confirmed that the artificial aging did not influence the strength in compression parallel to the grains and the hardness perpendicular to the grain of the considered wood species.

Figure 5 shows that all mechanical properties were influenced by the natural weathering treatment (p-value $<0.05$ ). The properties $E_{\mathrm{C}^{\prime}}, E_{\mathrm{T}}$, and $f_{\mathrm{m}}$ ' decreased with artificial and natural aging, but the property $L_{\mathrm{E}}$ ' increased with the same treatments, which led to an increase in wood brittleness.

Table 3 presents the confidence intervals of the linear regression models of $E_{\mathrm{C}}, E_{\mathrm{T}}$, $f_{\mathrm{m}}$, and $L_{\mathrm{E}}$, for the artificial and natural weathering treatments for the third level (384 h or 360 days, respectively).

Table 3. Confidence Intervals of Linear Regression Models for Affected Wood Properties

\begin{tabular}{|c|c|c|c|c|}
\hline \multicolumn{5}{|c|}{ Confidence Interval (95\% Confidence Level) } \\
\hline Property & Weathering & Lower Limit & Adjusted & Upper Limit \\
\hline ET' & Artificial & 0.8974 & 0.9266 & 0.9559 \\
\hline EC' $^{\prime}$ & Artificial & 0.8875 & 0.9168 & 0.9461 \\
\hline fm' $^{\prime}$ & Artificial & 0.8901 & 0.9342 & 0.9783 \\
\hline LE' $^{\prime}$ & Artificial & 1.1244 & 1.1599 & 1.1953 \\
\hline ET' & Natural & 0.8267 & 0.8645 & 0.9023 \\
\hline EC' & Natural & 0.833 & 0.8704 & 0.9078 \\
\hline fm' $^{\prime}$ & Natural & 0.7783 & 0.8243 & 0.8702 \\
\hline LE' $^{\mid}$ & Natural & 1.1529 & 1.1879 & 1.2229 \\
\hline
\end{tabular}

Based on the adjusted value of the linear regression model presented in Table 3, it was possible to calculate the percentage change of $E_{\mathrm{C}}, E_{\mathrm{T}}, f_{\mathrm{m}}$, and $L_{\mathrm{E}}$, for both artificial and natural aging. Table 4 presents these results.

Table 4. Percentage Change of Mechanical Performance with Aging Treatments

\begin{tabular}{|c|c|c|c|}
\hline Property & Artificial & Natural & Ratio \\
\hline$E_{\mathrm{T}}$ & $7.34 \%$ & $13.55 \%$ & 1.85 \\
\hline$E_{\mathrm{C}}$ & $8.32 \%$ & $12.96 \%$ & 1.56 \\
\hline$f_{\mathrm{m}}$ & $6.58 \%$ & $17.57 \%$ & 2.67 \\
\hline$L_{\mathrm{E}}$ & $15.99 \%$ & $18.79 \%$ & 1.18 \\
\hline Average & $9.56 \%$ & $15.72 \%$ & 1.81 \\
\hline
\end{tabular}


As Table 4 shows, the effects of 360 days of the natural weathering treatment was comparable to the effects of $384 \mathrm{~h}$ of the artificial weathering treatment. The average ratio between the effects for $E_{\mathrm{T}}, E_{\mathrm{C}}, f_{\mathrm{m}}$, and $L_{\mathrm{E}}$ (significant linear regression models) was 1.81 . Furthermore, based on this value, $384 \mathrm{~h}$ of artificial weathering (32 cycles) provided the effect of approximately 199 days of natural aging and one cycle of artificial weathering (12 h) corresponded to approximately 6.22 days of natural weathering exposure (for the same conditions).

\section{CONCLUSIONS}

1. The results from using the entire range of strength classes of ABNT NBR 7190 (1997), a paired sampling approach, and relative values provided an understanding of the weathering effects on the mechanical properties of wood.

2. The statistical analysis performed in this study made it possible to observe mechanical performance changes of the wood with the exposure time to the artificial and natural weathering treatments.

3. The natural weathering was carried out for one year in São Carlos, São Paulo State, Brazil, which covered the four seasons of the year and provided more consistent results to compare with the cycles of the artificial aging treatment.

4. The mechanical performance of the wood decreased $15.7 \%$ after 360 days of the natural weathering treatment based on the significant linear regression models.

5. A 12-h cycle of the artificial weathering treatment provided the effects of 6.22 days of natural weathering.

\section{ACKNOWLEDGMENTS}

The authors thank CAPES for the financial support (this study was financed by the Coordenação de Aperfeiçoamento de Pessoal de Nível Superior - Brasil (CAPES) - Finance Code 001) and the Laboratory of Wood and Timber Structures (LaMEM) of the Engineering of Structures Department (SET) of the Engineering School of São Carlos (EESC) - University of São Paulo (USP).

\section{REFERENCES CITED}

ABNT NBR 7190 (1997). “Design of timber structures,” Brazilian Technical Standards Association, Rio de Janeiro, Brazil.

Almeida, D. H., and Dias, A. A. (2016). "Comparison between test methods to determine wood embedment strength parallel to the grain,” Revista Árvore [Journal of Brazilian Forest Science] 40(4), 741-748. DOI: 10.1590/0100-67622016000400018

Almeida, T. H., Almeida, D. H., Christoforo, A. L., Chahud, E., Branco, L. A. M. N., and Lahr, F. A. R. (2016). "Density as estimator of strength in compression parallel to the grain in wood,” International Journal of Materials Engineering 6(3), 67-71. DOI: 10.5923/j.ijme.20160603.01 
Almeida, D. H., Almeida, T. H., Ferro, F. S., Christoforo, A. L., and Lahr, F. A. R. (2017a). "Compression strength of Brazilian exotics wood species perpendicular to the grain,” Journal of Civil Engineering Research 7(3), 105-107. DOI: 10.5923/j.jce.20170703.03

Almeida, T. H., Almeida, D. H., Araújo, V. A., Silva, S. A. M., Christoforo, A. L., and Lahr, F. A. R. (2017b). "Density as estimator of dimensional stability quantities of Brazilian tropical woods,” BioResources 12(3), 6579-6590. DOI: 10.15376/biores.12.3.6579-6590

ASTM G154 (2016). "Standard practice for operating fluorescent light apparatus for UV exposure of nonmetallic materials,” ASTM International, West Conshohocken, PA.

Baysal, E. (2012). "Surface characteristics of CCA treated Scots pine after accelerated weathering,” Wood Research 57(3), 375-382.

Calil, Jr., C., Lahr, F. A. R, and Dias, A. A. (2003). Dimensionamento de Elementos Estruturais de Madeira [Dimensioning of Wood Structural Elements], Manole, São Paulo, Brazil.

Cogulet, A., Blanchet, P., and Landry, V. (2016). "Wood degradation under UV irradiation: A lignin characterization,” Journal of Photochemistry and Photobiology B: Biology 158, 184-191. DOI: 10.1016/j.jphotobiol.2016.02.030

Fechine, G. J. M., Santos, J. A. B., and Rabello, M. S. (2006). “Avaliação da fotodegradação de poliolefinas através de exposição natural e artificial [Evaluation of photodegradation of polyolefins through natural and artificial exposure]," Química Nova 29(4), 674-680.

Ganne-Chédeville, C., Jääskeläinen, A., Froidevaux, J., Hughes, M., and Navi, P. (2012). "Natural and artificial ageing of spruce wood as observed by FTIR-ATR and UVRR spectroscopy,” Holzforschung 66(2), 163-170. DOI: 10.1515/hf.2011.148

George, B., Suttie, E., Merlin, A., and Deglise, X. (2005). "Photodegradation and photostabilisation of wood - The state of the art," Polymer Degradation and Stability 88(2), 268-274. DOI: 10.1016/j.polymdegradstab.2004.10.018

Hansmann, C., Deka, M., Wimmer, R., and Gindl, W. (2006). “Artificial weathering of wood surfaces modified by melamine formaldehyde resins," Holz als Roh- und Werkstoff 64(3), 198-203. DOI: 10.1007/s00107-005-0047-y

Miklečić, J., and Jirouk-Rajković, V. (2011). "Accelerated weathering of coated and uncoated beech wood modified with citric acid,” Drvna Industrija 62(4), 277-282. DOI: 10.5552/drind.2011.1116

Mohebby, B., and Saei, A. M. (2015). "Effects of geographical directions and climatological parameters on natural weathering of fir wood," Construction and Building Materials 94, 684-690. DOI: 10.1016/j.conbuildmat.2015.07.049

Oberhofnerová, E., Pánek, M., and García-Cimarras, A. (2017). “The effect of natural weathering on untreated wood surface,” Maderas. Ciencia y Tecnología [Woods Science and Technology] 19(2), 173-184. DOI: 10.4067/S0718-221X2017005000015

Pandey, K. K. (2005). "Study of the effect of photo-irradiation on the surface chemistry of wood," Polymer Degradation and Stability 90(1), 9-20. DOI:

10.1016/j.polymdegradstab.2005.02.009

R Core Team. (2018). R: A language and environment for statistical computing, $\mathrm{R}$ Foundation for Statistical Computing, (https://www.R-project.org/). Accessed 032019.

Rodríguez-Anda, R., and Fuentes-Talavera, F. J. (2003). "Factores que intervienen en el proceso de envejecimiento de la madera [Factors that influence the aging process of 
wood],” Revista Chapingo: Serie Ciencias Forestales y del Ambiente [Chapingo journal: Forestry and Environment Sciences Series] 9(1), 95-100.

Rosu, D., Teaca, C., Bodirlau, R., and Rosu, L. (2010). "FTIR and color change of the modified wood as a result of artificial light irradiation," Journal of Photochemistry and Photobiology B: Biology 99(3), 144-149. DOI: 10.1016/j.jphotobiol.2010.03.010

Teodorescu, I., Țăpuși, D., Erbașu, R., Bastidas-Arteaga, E., and Aoues, Y. (2017). "Influence of the climatic changes on wood structures behavior," Energy Procedia 112, 450-459. DOI: 10.1016/j.egypro.2017.03.1112

Viitanen, H., Toratti, T., Makkonen, L., Thelandersson, S., Isaksson, T., Früwald, E., Jermer, J., Englund, F., and Suttie, E. (2011). "Modelling of service life and durability of wooden structure," in: $9^{\text {th }}$ Nordic Symposium on Building Physics, Tampere, Finland, pp. 925-932.

Yildiz, S., Tomak, E. D., Yildiz, U. C., and Ustaomer, D. (2013). "Effect of artificial weathering on the properties of heat treated wood," Polymer Degradation and Stability 98(8), 1419-1427. DOI: 10.1016/j.polymdegradstab.2013.05.004

Yildiz, S., Yildiz, U. C., and Tomak, E. D. (2011). "The effect of natural weathering on the properties of heat-treated alder wood," BioResources 6(3), 2504-2521. DOI: 10.15376/biores.6.3.2504-2521

Article submitted: December 18, 2018; Peer review completed: April 9, 2019; Revisions accepted: June 11, 2019; Published: June 19, 2019.

DOI: 10.15376/biores.14.3.6267-6277 